\title{
Alternate strategies for improving iron nutrition: lessons from recent research
}

\author{
K. Madhavan Nair \\ Department of Biophysics, National Institute of Nutrition, Indian Council of Medical Research, Jamai Osmania P.O., \\ Hyderabad - 500007, India
}

\begin{abstract}
Strategies such as dietary diversification and food fortification have yielded significant results in controlling iron deficiency anaemia in developed countries. Reducing the prevalence of iron deficiency anaemia in developing countries is still a matter of importance. The major factors responsible for iron deficiency anaemia in the vulnerable segments of developing countries are reduced intake and poor bioavailability of dietary iron. Dietary diversification and food-based approaches pose considerable challenges before they can be implemented on a wide scale. Anaemia control programmes based on the administration of prophylactic doses of iron and folic acid tablets have been widely implemented. As the programmes were not effective in countries such as India, the dosage of iron was increased. The role of excess iron in causing intestinal oxidative stress has drawn attention to other approaches of iron supplementation. Prophylactic administration of iron along with antioxidants like vitamins $\mathrm{E}$ and $\mathrm{C}$ or foods rich in these vitamins is one such strategy. To reduce the intestinal oxidative stress, intermittent supplementation of iron is being considered. The potential benefits and shortcomings of these approaches are reviewed.
\end{abstract}

Iron supplementation: Alternate strategies: Oxidative stress: Vitamin E: Ascorbic acid: Intermittent iron supplementation

The major determinants of widespread prevalence of nutritional anaemia are inadequate intake and poor bioavailability of dietary iron. Despite a seemingly satisfactory overall intake of iron in diets (based on RDA), iron deficiency anaemia is widespread. Poor bioavailability of iron $(2.6-3.6 \%)$ in cereal-based diets appears to be the major responsible factor (Rao et al. 1983). Increased demand for iron during periods of growth accentuates iron deficiency anaemia and for this reason, iron deficiency is a major public health problem in young children and women of child bearing age in developing countries. Considering the health implications of iron deficiency anaemia, many countries have adopted prophylactic measures such as the former National Nutritional Anaemia Prophylaxis Programme or the current National Nutritional Anaemia Control Programme in India, based on WHO recommendations. The benefits of such large-scale supplementation programmes are yet to be realised (Seshadri, 1997). Among other factors, logistic problems are reported to be responsible for the less than expected impact of the programme (ICMR Task Force Studies, 1989; 1992). The need to either improve impact of current iron supplementation programmes or to find alternative strategies for increasing iron intake is widely felt.

\section{Some concerns related to iron deficiency control measures}

While recognising the overall importance of increasing iron intake by vulnerable sections, we need to be aware that our expectations in some instances may be exaggerated.

There is concern that supplementation programmes would not substantially improve birth weight. Further, there is little evidence to show that iron supplementation during pregnancy can minimise the risk of adverse pregnancy outcomes. Although studies (Zhou et al. 1998; Steer et al. 1995) suggest that pregnant women with anaemia $(\mathrm{Hb}<100 \mathrm{~g} / \mathrm{L})$ have a higher risk for preterm birth and low birth weight, it is not clear to what extent anaemia is responsible for these outcomes and whether iron supplementation substantially ameliorates these problems. The prevalence rates of preterm birth and low birth weight have been related in a U-shaped curve with haemoglobin levels at the time of enrolment. The lowest risk was found in women with haemoglobin 110-119 g/L (Zhou et al. 1998) and an increased risk with other haemoglobin levels. Based on a meta analysis of pregnancy anaemia and low birth weight, Steer et al. (1995) have suggested that the pregnancy haemoglobin values of $100-110 \mathrm{~g} / \mathrm{L}$ are likely 
to reflect good maternal response to pregnancy more than poor iron status. Similarly the relative risk of low birth weight was close to unity at haemoglobin values ranging from 90 to $120 \mathrm{~g} / \mathrm{L}$. This raises an additional concern that routine iron supplementation to all pregnant women would elevate haemoglobin of non-anaemic women to levels that may actually carry higher risk of adverse birth outcomes.

There are other issues that merit consideration when future strategies for delivering iron through supplementation or other approaches are considered. Absorption of iron is a highly regulated process and due to this a large fraction of the iron supplement administered daily remains unabsorbed in the small intestine. Continuous exposure of the intestine to iron is believed to reduce iron absorption from subsequent doses (Fairweather-Tait et al. 1985). Thus, the issue of exposing the intestine to large amounts of supplementary iron generating free radicals via the Fenton reaction and thus leading to oxidative damage of the tissues has come into focus (Slivka et al. 1986). This is particularly important, considering the meagre intake of antioxidants by the target groups in developing countries.

Promoting adequate iron nutrition in communities that are at risk of iron deficiency is possible through fortification of dietary staples with added iron. In India, common salt has been identified as the appropriate vehicle for iron fortification (Nadiger et al. 1980; Report of the Working Group on Salt Fortification with Iron, 1982). Although the positive impact of salt fortified with iron has been shown, the reported mean iron absorption from the fortified salt determined in normal children was found to be $3.4 \%$ which was similar to that obtained from a cereal based diet (Nadiger et al. 1980). It is logical to consider that on predominantly cereal based diets, having poor iron, the exogenously added iron is equally poorly absorbed (Hallberg et al. 1974). The major concern, thus, is the persistent role of less recognised factors limiting absorption of iron. Also the introduction of the universal iodisation of edible salt has sidelined the possible implementation of iron fortified salt as a National programme in India.

\section{Mucosal response to iron supplement}

Though there is evidence of a positive impact of iron supplementation in properly conducted clinical trials, the results obtained with large scale public health programmes have been variable (Baynes \& Cook, 1996; Yip, 1996). Gastrointestinal side-effects to oral iron leading to poor compliance is believed to be the main reason. Although there are many factors that could contribute to the ineffectiveness of iron supplementation in public health programmes, it is unclear to what extent the failure of such 'real-life' programmes is due to the response of the intestinal absorptive surface to repeated high doses of iron, particularly in the nutritionally compromised intestine of the populations in developing countries.

\section{Intestinal iron absorption}

Iron absorption is a self-regulating step in the physiology of iron. No well established mechanisms have been elucidated. Studies in animal models and with human intestinal biopsy samples, provided the evidence for the possible role of transferrin receptor mediated uptake of iron (Vasantha Lakshmi, 1998). Iron deficient intestines exhibited greater concentration of the transferrin receptor. Functionally this is expected to increase iron absorption through a luminal transferrin-mucosal transferrin receptor system. It is not known whether there is any increased burden on the receptor during daily therapeutic regimen of iron.

\section{Iron supplementation and oxidative damage of the gastrointestinal tract}

Recent studies have shown that repletion of iron deficient rats with iron promotes oxidative stress, damages the absorptive cells and brings about functional and ultrastructural derangements in the intestine. The causative factor responsible for such effects was identified as the hydroxyl radical produced by excess iron at the site of iron absorption (Srigiridhar \& Nair, 1998 and unpublished observations). The findings on the role of food per se (natural diet) in reducing the effects of iron mediated oxidative stress has practical relevance (Srigiridhar \& Nair, 1997).

\section{Protective effects of antioxidants on iron mediated oxidative damage of the gastrointestinal tract}

Oral administration of vehicle (D) or $8 \mathrm{mg}$ of iron alone $\left(\mathrm{D}^{+}\right)$or in the presence of $40 \mathrm{mg} \alpha$-tocopherol $\left(\mathrm{D}^{+}\right.$and $\left.\mathrm{E}\right)$ or $24 \mathrm{mg}$ of ascorbic acid $\left(\mathrm{D}^{+}\right.$and $\left.\mathrm{C}\right)$ or a combination of both ( $\mathrm{D}^{+}$and $\mathrm{C}$ and $\mathrm{E}$ ) per day for 15 days was carried out in iron depleted rats and the protective role studied (Srigiridhar \& Nair, 2000). The indicators of iron status were normalised on iron supplementation either with or without antioxidants and the haemoglobin regenerated was greatest in groups that received vitamin $\mathrm{C}$ than in $\mathrm{D}^{+}$and $\mathrm{D}^{+}$and $\mathrm{E}$ groups. The liver and serum iron concentrations were greater in the $\mathrm{D}^{+}$and $\mathrm{C}$ group than the other supplemented groups (Table 1). Normalisation of functional integrity was observed in all the groups treated with antioxidant(s). However, the groups which received vitamin $\mathrm{E}\left(\mathrm{D}^{+}\right.$and $\mathrm{E}, \mathrm{D}^{+}$and $\mathrm{C}$ and $\left.\mathrm{E}\right)$ only had lower levels of thiobarbituric acid reactive substances (TBARS) and protein carbonyls in the gastrointestinal tract (Table 2). Degraded mucosal cell DNA was observed in $\mathrm{D}^{+}, \mathrm{D}^{+}$and $\mathrm{C}$ and $\mathrm{D}^{+}$and $\mathrm{E}$ groups. The alterations in endogenous antiperoxidative system induced by excess iron were reduced by antioxidant supplementation. Serum ascorbate levels were significantly lowered in $\mathrm{D}^{+}$and $\mathrm{C}$ group (Table 2). But in the presence of $\alpha$-tocopherol, serum ascorbate levels were significantly elevated suggesting that there is an effective protection offered by $\alpha$-tocopherol in maintaining serum ascorbate levels. These findings indicate that, when iron deficient rats are repleted with high doses of iron along with both vitamins $\mathrm{C}$ and $\mathrm{E}$, almost all key adverse effects are reversed (Srigiridhar \& Nair, 2000). Combined supplementation of $\alpha$-tocopherol and ascorbic acid rather than individual vitamins protected the gastrointestinal tract of iron deficient rats against iron mediated free radical damage during repletion.

To what extent the iron induced gastrointestinal tract 
Table 1. Effect of supplementation of iron and antioxidants on haemoglobin, liver and serum iron levels

\begin{tabular}{|c|c|c|c|}
\hline Treatment & $\begin{array}{l}\text { Haemoglobin } \\
(\mathrm{g} / \mathrm{L})\end{array}$ & $\begin{array}{c}\text { Liver iron } \\
(\mu \mathrm{mol} / \mathrm{g} \text { tissue })\end{array}$ & $\begin{array}{c}\text { Serum iron } \\
(\mu \mathrm{mol} / \mathrm{L})\end{array}$ \\
\hline Con & $152^{\mathrm{a}}+4.5$ & $32^{a} \pm 6 \cdot 6$ & $69^{a} \pm 14 \cdot 3$ \\
\hline D & $79^{\mathrm{b}} \pm 7 \cdot 2$ & $15^{b} \pm 4 \cdot 7$ & $31^{b} \pm 5.5$ \\
\hline$D^{+}$ & $147^{\mathrm{c}, \mathrm{e}} \pm 3 \cdot 3$ & $65^{c} \pm 3 \cdot 1$ & $80^{a} \pm 6 \cdot 4$ \\
\hline $\mathrm{D}^{+}+\mathrm{C}$ & $\begin{array}{c}151^{\mathrm{a}, \mathrm{c}, \mathrm{d}^{\prime}} \pm 5 \cdot 1 \\
(9)\end{array}$ & $85^{d} \underset{ \pm}{ \pm} 12 \cdot 2$ & $72^{a} \pm 10 \cdot 0$ \\
\hline $\mathrm{D}^{+}+\mathrm{E}$ & $\begin{array}{c}146^{\mathrm{e}} \pm 2 \cdot 5 \\
(10)\end{array}$ & $68^{c} \pm 18 \cdot 4$ & $46^{c} \pm 10 \cdot 2$ \\
\hline $\mathrm{D}^{+}+\mathrm{C}+\mathrm{E}$ & $\begin{array}{c}148^{\mathrm{a}, \mathrm{c}, \mathrm{e}} \pm 4 \cdot 2 \\
(9)\end{array}$ & $66^{c} \pm 15.7$ & $50^{\mathrm{C}} \underset{(5)}{ \pm}$ \\
\hline
\end{tabular}

Values are Mean \pm SD $(n)$

Values with different superscript letters within a given column differ significantly by ANOVA $(P<0.05)$.

Abbreviations: Con, control; $\mathrm{D}$, iron deficient; $\mathrm{D}^{+}$, iron deficient supplemented with iron; $\mathrm{D}^{+}+C$, same as $\mathrm{D}^{+}$plus vitamin $\mathrm{C} ; \mathrm{D}^{+}+\mathrm{E}$, same as $\mathrm{D}^{+}$plus vitamin $E ; D^{+}+C+E$, same as $D^{+}$plus vitamins $C$ and $E$

Source: Srigiridhar \& Nair, 2000.

discomfort is due to this increased oxidative stress is not known.

\section{Intermittent iron supplementation as a strategy}

Many new findings have been obtained using alternate strategies of iron supplementation. In experimental animals, the absorption of oral iron is greatest when it is administered synchronised with the intestinal mucosal cell turnover, so that each dose is received by new cells (Fairweather-Tait et al. 1985). This finding is supported by the observed functional and structural changes brought about by daily supplementation of excess iron (Srigiridhar \& Nair, 1998). In this context, the comparable effectiveness of intermittent iron supplementation to that of daily administration has practical relevance. This strategy could reduce the possible inhibitory effects of iron on its absorption and also protect the intestine from the unwarranted exposure to large doses of iron.
Studies conducted in preschool children and pregnant women showed that iron supplementation weekly or intermittently can be as effective as daily supplementation. The compliance rate was nine and seven times higher than that of the daily dose with the weekly supplementation in children (Liu et al.1995a) and in pregnant women (Liu et al. $1995 b)$ respectively. Ridwan et al. (1996) supplemented pregnant women who were 8-24 weeks of gestation with either weekly $(120 \mathrm{mg})$ or daily $(60 \mathrm{mg})$ doses and reported no difference in response to these two modes of supplementation. The changes in haemoglobin were 4 and $6 \mathrm{~g} / \mathrm{L}$ respectively in daily and weekly supplemented groups. In a recent study in Malaysian adolescent schoolgirls, Tee et al. (1999) concluded that long-term (22 weeks) weekly supplementation with iron and folate improves their iron stores and haemoglobin concentration. The final haemoglobin response to iron-folate supplements was significant and varied between 11.2 and $15.5 \mathrm{~g} / \mathrm{L}$ depending on the initial serum ferritin levels. It may be noted that the authors of this study did not include a group receiving daily supplements to conclude on the merits of weekly supplementation of iron. Compliance with the supplementation protocol was excellent (96\%) in this study and was mainly due to the active participation of teachers.

The effect of weekly supplementation of iron along with vitamins A, C and folic acid was investigated by AngelesAgdeppa et al. (1997). The study was carried out in East Jakarta in senior high school girls (age 16.8 \pm 0.94 ) who were anaemic $(\mathrm{Hb}<120 \mathrm{~g} / \mathrm{L})$. The study group consisted of a group $(n=64)$ receiving $60 \mathrm{mg}$ iron, $750 \mu \mathrm{g}$ retinol, $60 \mathrm{mg}$ vitamin $\mathrm{C}$ and $250 \mathrm{mg}$ folate (daily dose) while the low $(n=70)$ and high $(n=64)$ iron weekly groups received 60 and $120 \mathrm{mg}$ of iron respectively in addition to $6000 \mu \mathrm{g}$ retinol, $60 \mathrm{mg}$ vitamin $\mathrm{C}$ and $500 \mathrm{mg}$ folic acid. A placebo group $(n=75)$ was also included in the study. The supplements were given under supervision for the initial 4 weeks of the 12 -week intervention. The results at the end of 8 and 12 weeks of supplementation indicated increase in haemoglobin of $5 \mathrm{~g} / \mathrm{L}$ with high dose, $6 \cdot 1 \mathrm{~g} / \mathrm{L}$ with low dose and $6.3 \mathrm{~g} / \mathrm{L}$ with daily dose. However, the increase in serum ferritin concentration of the subjects

Table 2. Effect of antioxidants on lipid peroxidation, protein oxidation, serum ascorbate and $\alpha$-tocopherol levels during iron supplementation in iron depleted rats

\begin{tabular}{|c|c|c|c|c|}
\hline Treatment & $\begin{array}{c}\text { TBARS } \\
\text { (nmol MDA/mg protein) }\end{array}$ & $\begin{array}{l}\text { Protein carbonyls } \\
\text { (nmol/mg protein) }\end{array}$ & $\begin{array}{l}\text { Serum ascorbate } \\
(\mu \mathrm{mol} / L)\end{array}$ & $\begin{array}{c}\text { Serum } \alpha \text {-tocophero } \\
(\mu \mathrm{mol} / \mathrm{L})\end{array}$ \\
\hline Con & $0.82^{a} \pm 0.25$ & $0.96^{\mathrm{a}, \mathrm{e}} \pm 0.31$ & $34^{\mathrm{a}, \mathrm{c}} \pm 16 \cdot 9$ & $2 \cdot 4^{a, c} \pm 0.82$ \\
\hline D & $0.56^{b} \pm 0.19$ & $0.95^{a, b} \pm 0.25$ & $26^{a, b} \pm 9 \cdot 3$ & $2.9^{a} \pm 0.80$ \\
\hline$D^{+}$ & $\begin{array}{c}1.63^{c} \pm 0.24 \\
(7)\end{array}$ & $2.06^{c} \pm 0.56$ & $\begin{array}{c}17^{b} \pm 5 \cdot 6 \\
(7)\end{array}$ & $4.9^{\mathrm{b}} \pm 0.74$ \\
\hline $\mathrm{D}^{+}+\mathrm{C}$ & $1.72^{c} \pm 0.32$ & $2 \cdot 12^{c} \pm 0.82$ & $26^{a, b} \pm 6 \cdot 2$ & $0.72^{c} \pm 0.28$ \\
\hline $\mathrm{D}^{+}+\mathrm{E}$ & $1 \cdot 21^{d} \pm 0.16$ & $1.02^{d} \pm 0.40$ & $47^{\mathrm{c}, \mathrm{d}} \pm 17 \cdot 8$ & $6 \cdot 1^{\mathrm{b}} \pm 2 \cdot 00$ \\
\hline $\mathrm{D}^{+}+\mathrm{C}+\mathrm{E}$ & $\begin{array}{c}1.37^{d} \pm 0.24 \\
(7)\end{array}$ & $\begin{array}{c}1 \cdot 16^{\mathrm{d}, \mathrm{e}} \pm 0.21 \\
(7)\end{array}$ & $\begin{array}{c}53^{d} \pm 23 \cdot 9 \\
(7)\end{array}$ & $5 \cdot 6^{\mathrm{b}} \pm 1.48$ \\
\hline
\end{tabular}

Values are Mean $\pm \mathrm{SD}(n)$.

Values with different superscript letters within a given column differ significantly by ANOVA $(P<0.05)$

Abbreviations: Con, control; $D$, iron deficient; $D^{+}$, iron deficient supplemented with iron; $D^{+}+C$, same as $D^{+}$plus vitamin $C$; $D^{+}+E$, same as $D^{+}$plus vitamin $E$; $\mathrm{D}^{+}+\mathrm{C}+\mathrm{E}$, same as $\mathrm{D}^{+}$plus vitamins $\mathrm{C}$ and $\mathrm{E}$, TBARS, thiobarbituric acid reactive substances; MDA, malonaldehyde.

Source: Srigiridhar \& Nair, 2000. 
supplemented daily was $12-13 \mu \mathrm{g} / \mathrm{L}$ higher than that of the subjects supplemented weekly. Though there is no direct proof for the effects of supplementation of these micronutrient on absorption, weekly supplementation with $60 \mathrm{mg}$ iron and $6000 \mu \mathrm{g}$ retinol may have been more effective in building iron stores.

The major criticism of the studies on efficacy of intermittent iron supplementation is that the studies have not been carried out under programmatic conditions. Beaton et al. (1999) compared the results of such studies and showed that the relative risk estimate is greater than unity $(0 \cdot 87-1 \cdot 61)$ when expressed as the ratio of prevalence of anaemia among those receiving weekly supplementation to that of those given daily supplementation. Though there were similar responses in haemoglobin, the impact on prevalence of anaemia seems to be different between the groups, which received intermittent and daily iron supplementation. Based on this the authors concluded that weekly iron supplementation is likely to be less effective than daily administration except in situations where supervision is feasible with weekly regimens and not with daily supplementation. Further, regardless of the degree of supervision that can be arranged, weekly, instead of daily, iron administration is not recommended for pregnancy.

The importance of achieving good compliance thus seems to be the part of such intervention studies. The study of Tee et al. (1999) confirms the strategy of long-term weekly iron-folate supplementation as a practical, safe, effective and inexpensive method for improving iron nutrition in adolescent girls. Based on this study, Picciano (1999) suggested that such studies should serve as a prototype for future studies aimed at eliminating iron deficiency.

\section{Food based strategy}

The primary objective of this strategy is to focus on the adequacy of food availability to meet the nutritional needs of vulnerable populations. This necessarily implies consumption of adequate food. This can only be achieved through programmes aimed to alleviate poverty. Once this is met, the bioavailability of iron can be improved by dietary diversification through food sources that supply ascorbic acid such as citrus fruits and green leafy vegetables.

\section{Food fortification}

\section{Staple foods}

Fortification of suitable staple food items with iron seems to be a good approach. The success stories of mandatory wheat flour fortification in developed countries needs only to be duplicated in developing countries. But the dynamics of operation, outreach and availability in remote places need to be established first. This strategy not only provides extra iron but also assures food, if made available at an affordable price.

\section{Common salt}

Fortification of common salt with iron or doubly fortified with iron and iodine is a cheap and good strategy but has the disadvantage of not being a food item that provides energy. The Working Group on Fortification of Salt with Iron (1982) conducted a large study that followed a small pilot study in school children (Nadiger et al. 1980). These studies proved the stability of the product, tolerance and efficacy in increasing haemoglobin levels. The communitybased study evaluated the effect of iron-fortified salt on haemoglobin levels in rural and urban centres at the end of 1 year. The results suggested progressive increase in haemoglobin reaching an average of about $10-30 \mathrm{~g} / \mathrm{L}$ after 1 year in rural centres and $5 \mathrm{~g} / \mathrm{L}$ in urban centres. However, due to the introduction of universal iodisation of edible salt in India, a technology for double fortification of common salt (DFS) was developed subsequently (Narasinga Rao, 1994). The impact of DFS was tested in a tribal community based intervention and another cohort study. The results of the tribal community study suggest the operational feasibility of distribution of DFS in the community. There was, however, a similar response in haemoglobin levels in both the control and DFS supplemented groups (Nair et al. 1998). However, the cohort school study clearly demonstrated an improvement in haemoglobin in mild-moderate anaemics (Hb 100-120 g/ $\mathrm{L})$ than in those with levels greater than $120 \mathrm{~g} / \mathrm{L}$. There appears to be no additional benefit of DFS supplementation in those with normal status (Brahmam et al. 2000). Both the studies were carried out for $2 \mathrm{y}$. Further studies are in progress in India to ascertain both the stability of iodine in double fortified salt as well as the impact on haemoglobin status of the population. Due to regional differences and preferences in food consumption patterns, it is indeed difficult to have an ideal food vehicle other than salt for iron fortification in India. The possibility of fortification of regionally preferred staple food items could be selected and made into an alternate strategy.

\section{Fortification with iron absorption promoters}

The dietary factors that restrict absorption of intrinsic iron in foods have a similar effect on the added iron. A number of inhibitory ligands have been identified. Indian diets have consistently revealed iron content considerably in excess of those predicted from food tables (Soni \& Sharma, 1974). These considerations have led to the suggestion that a more rational approach to the correction of iron deficiency would be to render the intrinsic dietary iron more available by adding ligands which promote iron absorption such as ascorbic acid (Hallberg et al. 1974; Derman et al. 1977). While this approach would obviously be of limited value in situations where the dietary iron content is low, some cereal based diets consumed by iron deficient populations have been shown to contain apparently adequate quantities of iron. Sodium iron EDTA is a promising iron compound for food fortification programmes because of its high iron bioavailability from meal containing dietary inhibitors of iron absorption such as phytic acid (MacPhail et al. 1994). 


\section{Conclusions}

Normalisation of functional integrity and oxidative stress could be achieved when the intestine was preconditioned with the antioxidant(s) $\alpha$-tocopherol and ascorbic acid during repletion with excess iron. It is suggested that daily administration of therapeutic doses of iron may be accompanied by supplementation with combination of ascorbic acid and $\alpha$-tocopherol or with a meal of natural ingredients having high amounts of these vitamins (food) to reduce the oxidative stress. Administration of iron intermittently rather than daily is a useful strategy that may minimise undesired side effects. This approach probably needs to be introduced as part of other health care delivery systems or school programmes wherein a certain degree of supervision can be ensured. Further evaluation studies are essential to be carried out under programmatic conditions. Poverty eradication to meet the nutritional requirements, followed by dietary diversification and food fortification are the other priorities required to control iron deficiency in developing countries.

\section{References}

Angeles-Agdeppa I, Schultink W, Sastraomidjojo S, Gross R \& Karyad D (1997) Weekly micronutrient supplementation to build iron stores in female Indonesian adolescents. American Journal of Clinical Nutrition 66, 177-183.

Baynes RD \& Cook JD (1996) Current issues of iron deficiency. Current Opinion in Hematology 3, 145-149.

Beaton G, McCabe G, Yir R \& Zlotkin S (1999) Efficacy of intermittent iron supplementation in the control of iron deficiency anaemia in developing countries. Summary of major findings. Report prepared for release at the INACG meeting, March 1999.

Brahmam GNV, Madhavan Nair K, Laxmaiah A, Gal Reddy Ch, Ranganathan S, Vishnuvardhana Rao M, Nadamuni Naidu A, Vijayaraghavan K \& Sivakumar B (2000) Community trials with iron and iodine fortified salt (double fortified salt). In Proceedings of the 8th World Salt Symposium, pp. 955-960 [RM Geertman, editor]. Amsterdam: Elsevier.

Derman D, Sayers M, Lynch SR, Charlton RW \& Bothwell TH (1977) Iron absorption from a cereal-based meal containing cane sugar fortified with ascorbic acid. British Journal of Nutrition 38, 261-269.

Fairweather-Tait SJ, Swindell TT \& Wright AJA (1985) Further studies in rats on the influence of iron intake on the estimation of bioavailability of Fe. British Journal of Nutrition 54, 79-86.

Hallberg L, Garby L, Suwanik R \& Bjorn-Rasmussen E (1974) Iron absorption from South-East Asian diets. American Journal of Clinical Nutrition 27, 826-836.

ICMR Task Force study (1989) Evaluation of the National Nutritional Anaemia Prophylaxis Programme. New Delhi: Indian Council of Medical Research.

ICMR Task Force Study (1992) Field supplementation trial in pregnant women with $60 \mathrm{mg}, 120 \mathrm{mg}$ and $180 \mathrm{mg}$ of iron with $500 \mu \mathrm{g}$ folic acid. New Delhi: Indian Council of Medical Research.

Liu XN, Kang J, Zhao L \& Viteri FE (1995a) Intermittent iron supplementation in Chinese preschool children is efficient and safe. Food and Nutrition Bulletin 16, 139-146.

Liu XN, Yang WJ, Zhang H, Ying YG, Xie J \& Vitteri FE (1995b) Weekly iron supplementation is effective and safe in pregnant women. FASEB Journal 9, A5658.

Mac Phail PA, Patel RC, Bothwell TH \& Lamparelli RD (1994)
EDTA and the absorption of iron from food. American Journal of Clinical Nutrition 59, 644-648.

Nadiger HA, Krishnamachari KAVR, Nadamuni Naidu A, Narasinga Rao BS \& Srikantia SG (1980) The effect of common salt (sodium chloride) fortified with iron to control anaemia: results of a preliminary study. British Journal of Nutrition 43, 45-51.

Nair KM, Brahmam GNV, Ranganathan S, Vijayaraghavan K, Sivakumar B \& Krishnaswamy K (1998) Impact evaluation of iron and iodine fortified salt. Indian Journal of Medical Research 108, 203-211.

Narasinga Rao BS (1994) Fortification of salt with iron and iodine to control anemia and goitre. Development of a new formula with good stability and bioavailability of iron and iodine. Food and Nutrition Bulletin 15, 32-39.

Picciano MF (1999) Editorial: Iron and folate supplementation: an effective intervention in adolescent females. American Journal of Clinical Nutrition 69, 1069-1070.

Rao BSN, Vijayasarathy C \& Prabhavathi T (1983) Iron absorption from habitual diets of Indians studied by extrinsic tag techniques. Indian Journal of Medical Research 77, 648-657.

Report of the Working Group on Fortification of Salt with Iron (1982) Use of common salt fortified with iron in the control and prevention of anaemia - a collaborative study. American Journal of Clinical Nutrition 35, 1442-1451.

Ridwan E, Schultink W, Dillon D \& Gross R (1996) Effects of weekly iron supplementation on pregnant Indonesian women are similar to those of daily supplementation. American Journal of Clinical Nutrition 63, 884-890.

Seshadri S (1997) Nutritional anaemia in South Asia. In Malnutrition in South Asia. A Regional Profile, No. 5 [S Gillespie, editor]. UNICEF, Regional Office of South Asia.

Slivka A, Kang J \& Cohen G (1986) Hydroxyl radicals and the toxicity of oral iron. Biochemical Pharmacology 35, 553-556.

Soni BL \& Sharma DC (1974) Total and ionizable iron in common Indian cooked foods. American Journal of Clinical Nutrition 27, 455-457.

Srigiridhar K \& Nair KM (1997) Protective effects of antioxidant enzymes and GSH in vivo on iron mediated lipid peroxidation in gastrointestinal tract of rat. Indian Journal of Biochemistry and Biophysics 34, 402-405.

Srigiridhar K \& Nair KM (1998) Iron deficient intestine is more susceptible to peroxidative damage during iron supplementation in rats. Free Radical Biology and Medicine 25, 660-665.

Srigiridhar K \& Nair KM (2000) Supplementation with $\alpha$ tocopherol or a combination of $\alpha$-tocopherol and ascorbic acid protects the gastrointestinal tract of iron deficient rats against iron induced oxidative damage during iron repletion. British Journal of Nutrition 83, 165-173.

Steer P, Alam AM, Wadsworth J \& Welch A (1995) Relationship between maternal haemoglobin concentration and birth weight in different ethnic groups. British Medical Journal 310, 489-491.

Tee ES, Kandiah M, Awin N, Chong SM, Satgunasingam N, Kamarudin L, Milani S, Dugdale AE \& Veteri FE (1999) School-administered weekly iron-folate supplements improve haemoglobin and ferritin concentrations in Malaysian adolescent girls. American Journal of Clinical Nutrition 69, 1249-1256.

Vasantha Lakshmi K (1998) Interactions amongst transferrin, ferritin and other iron binding proteins during iron absorption. $\mathrm{PhD}$ thesis: Faculty of Science (Biochemistry), Osmania University, Hyderabad, India.

Yip R (1996) Iron supplementation during pregnancy: is it effective? American Journal of Clinical Nutrition 63, 853-855.

Zhou LM, Yang WW, Hua JZ, Deng CQ, Tao X \& Stoltzfus RJ (1998) Relationship of haemoglobin measured at different times in pregnancy to preterm birth and low birth weight in Shanghai, China. American Journal of Epidemiology 148, 998-1006. 